\title{
Bendable TN-LCD Using Transparent Polyimide Substrate
}

\author{
Gi Heon Kim and Won-Jae Lee \\ Electronics and Telecommunications Research Institute, Convergence Components \& Materials Research Lab., \\ 138 Gajeongno, Yuseong-Gu, Daejeon, 305-700, Korea \\ Fax: 82-42-860-5202, e-mail: kimgh411@etri.re.kr
}

Transparent colorless polyimide (C. PI) substrate with good optical transparency and high glass transition temperature was developed. To explore performance and process-ability, IZO (indium zinc oxide) pixel electrode was deposited onto the C. PI and the quality of IZO thin films in terms of sheet resistance and transparency was measured. We next fabricated 3-inch C.PI-based liquid crystal display (LCD) clock by mean of sheet-to-sheet freestanding process and investigated its electro-optic characteristics. The resulting LCD showed good electro-optic characteristics; contrast ratio and response time of on/off operation were 826:1 and $12.0 \mathrm{~ms}$, respectively.

Key words: Colorless Polyimide, Substrate, Flexible Display, LCD

\section{INTRODUCTION}

Nowadays, flexible electronics that require roll-ability or fold-ability of substrates are great interest in numerous technology areas. Many anticipated benefits of flexible electronics to be thinner, flexible, potential to be large, more shock resistance, light in terms of weight, and cheaper than glass-based electronics ${ }^{1) 2}$. A standard glass is lack of flexibility; however plastic substrates provide good robustness when dropped or twisted. Moreover potential benefits in using plastic substrates are freedom in electronic shapes, types and sizes.

However it is difficult task to use plastic films in current device fabrication process in films' original form. Plastic substrate has a several drawbacks; high coefficient of linear thermal expansion (CLTE) and thermal instability is much higher than that of glass, limiting manufacturing process, so that heating leads to considerable thermal stress ${ }^{3-6)}$.

The development of Polyimide (PI) opened many opportunities for the different industries. PI is considered one of the most stable polymer materials at high temperature ${ }^{1)}$. PI Film development and applications have been concentrated on FPCB (flexible printed circuit board), TAB (tape automated bonding) and heat-resistant insulator for electrical wire. For LCD (liquid crystal display) industry, PI has been used for an alignment layer material for LCs.

One of the shortcomings of the PI film for the application as display substrate would be the optical property of the PI film: color and optical transmittance. After imidization, PI mostly has yellow-brown color depending on the chemical composition. Highly conjugated structure and charge-transfer (CT) complex between the diamine (donor) and the dianhydride (acceptor) moieties in PI cause absorption in the UV-Visible region.

To make the PI transparent, it is necessary to introduce alkyl, aliphatic, alicyclic or separator $\left(-\mathrm{SO}_{2}\right)$ groups to reduce/eliminate electronic interactions and conjugations. A lot of efforts have been put into the development of colorless PI (C. PI) and only recently few companies started to produce colorless PI films for self-emitting or transmissive/reflective mode displays.

In this study, we demonstrate C. PI substrate that reduce electron affinity and overall conjugation with 2,2'-bis(3,4-carboxylphenyl) hexafluoropropane dianhydride (6FDA). The resulting C. PI has extremely high thermal stability and good chemical stability against various process chemicals during device fabrication. To explore performance and process-ability of this substrate, twisted nematic-LCD (TN-LCD) was fabricated and its electrical/optical properties were investigated.

\section{EXPERIMENTAL}

C. PI film (thickness, $100 \mu \mathrm{m}$ ) having uniform film thickness distribution, good optical quality and low CLTE, which is made by solvent cast method, was developed, and then explored its chemical/physical properties. Optical properties, such as haze, transmittance and yellow index, were measured at ambient temperature in air using HM-150 and Color $\mathrm{i}^{\mathrm{TM}} 5$. Surface roughness, which is basis for subsequent layer, was studied by atomic force microscopy (AFM). A silicon oxide layer (thickness, $100 \mathrm{~nm}$ ) as a gas barrier was deposited onto C. PI film by electron cyclotron resonance - chemical vapour deposition (ECR-CVD) in a high vacuum of $<10^{-6}$ Torr.

For analyzing characteristics of the C. PI film, a 3 -inch bendable TN-LCD clock was fabricated. The flexible LCD of transmission-mode, which is composed of two crossed polarizers and a nematic liquid crystal (NLC) layer, is formed as followed; C. PI substrate were washed with neutral detergent, distilled water and isopropyl alcohol (IPA) in an ultrasonic bath and then dried at $120^{\circ} \mathrm{C}$. An indium zinc oxide (IZO) electrode sputtered onto the substrate. Deposition at room temperature was performed in a pressure of $0.13 \mathrm{~Pa}$ by introducing Ar-sputternig gas and $\mathrm{O}_{2} / \mathrm{H}_{2}$ reactive gas into the process area ${ }^{7)}$. The power density was set to $700 \mathrm{~W} / \mathrm{cm}^{2}$. The quality of IZO thin layers in terms of electrical sheet resistance and clarity were measured by using sheet resistance measuring system (SPEC2000 and Loresta GP MCP-T600) with Jandel 4-point-probe, 
HM-150 (Haze, transmittance) and Color $\mathrm{i}^{\mathrm{TM}} 5$.

IZO electrode is clearly defined by a conventional photolithography technique. Soluble poly(amic acid) as an alignment layer was spin-coated onto the IZO-coated C. PI, and then was subsequently heated at $90{ }^{\circ} \mathrm{C}$ for 15 min and thermally imidized by heat treatment of $180{ }^{\circ} \mathrm{C}$ for $1 \mathrm{~h}$. The PI film thickness as an alignment layer was $120 \pm 3 \mathrm{~nm}$. The PI thickness was measured using a Tencor instrument Alpha-Step 500.

The NLC cell was assembly using a pair of the substrate prepared above ${ }^{9}$; these had been rubbed to obtain NLC alignment. The gap of the NLC cell was controlled by using $4 \mu \mathrm{m}$ thick photo (column) spacers formed on a bottom substrate by lithography process. NLC was introduced into the cell by mean of ODF (one drop filling) method. After NLC filling and following polarizer lamination proceeded. NLC (HHC06100-000) was purchased from Beijing Bay LCD Materials Technology Co. Ltd.

Electro-optic characteristics of C. PI-based LCDs were studied with Otsuka FPD-5200 system. Halogen lamp was used as a light source, and the transmittance at $550 \mathrm{~nm}$ was measured.

To evaluate cell gap uniformity, 9 points retardation measurements of the obtained LCDs were conducted.

\section{RESULTS AND DISCUSSION}

The C. PI substrate endured the high temperature $\left(\sim 180{ }^{\circ} \mathrm{C}\right)$ for thermal reaction of an alignment layer and photo spacers without going through dimensional change; to ensure precision registration of the different layers in the final device. CLTE is natural expansion of plastic films as temperature is cycled, which is 27 $\mathrm{ppm} /{ }^{\circ} \mathrm{C}$ over $50-250{ }^{\circ} \mathrm{C}$, even though a low CLTE typically $<10 \mathrm{ppm} /{ }^{\circ} \mathrm{C}$ is desirable to match thermal expansion of plastic film to the subsequently coated layers.

Table I. Physical properties of C. PI

\begin{tabular}{|c|c|c|}
\hline \multirow[b]{2}{*}{ 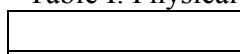 } & \\
\hline & Items & Results \\
\hline \multirow{3}{*}{ Optical properties } & $\begin{array}{l}\text { Transmittance } \\
\text { (at 550nm) }\end{array}$ & $92.4 \%$ \\
\hline & $\begin{array}{l}\text { Transmittance } \\
(380 \sim 740 \mathrm{~nm})\end{array}$ & $91.2 \%$ \\
\hline & Haze (at $550 \mathrm{~nm}$ ) & 0.3 \\
\hline \multirow{3}{*}{$\begin{array}{l}\mathrm{L} * \mathrm{a} * \mathrm{~b} * \text { Color } \\
\text { Space }\end{array}$} & $\mathrm{a}^{*}$ & -0.31 \\
\hline & $b^{*}$ & 2.84 \\
\hline & Yellow Index & 4.9 \\
\hline \multirow{4}{*}{$\begin{array}{l}\text { General } \\
\text { Properties }\end{array}$} & Film Density (g/cc) & 1.43 \\
\hline & Thickness $(\mu \mathrm{m})$ & 100 \\
\hline & $\begin{array}{c}\text { Water Absorption (\%) } \\
\left(23^{\circ} \mathrm{C}, 50 \%, 24 \mathrm{~h}\right)\end{array}$ & $<0.8$ \\
\hline & $\begin{array}{c}\text { Degree of } \\
\text { imidization }^{10)}\end{array}$ & $>99 \%$ \\
\hline \multirow{2}{*}{$\begin{array}{l}\text { Thermal } \\
\text { Properties }\end{array}$} & $\begin{array}{c}\mathrm{CLTE}\left(50 \sim 250^{\circ} \mathrm{C}\right) \\
\left(\mathrm{ppm} /{ }^{\circ} \mathrm{C}\right)\end{array}$ & 27 \\
\hline & $\begin{array}{l}\text { Glass Transition } \\
\text { Temperature }\left({ }^{\circ} \mathrm{C}\right)\end{array}$ & $>330$ \\
\hline
\end{tabular}

Clarity of the C. PI substrate, which is important for bottom-emitting/reflective mode display, shows light transmittance of $\sim 91 \%$ over $380-740 \mathrm{~nm}$. Its haze and yellow index were 0.2 and 4.9, respectively. Plastic film as a substrate must withstand thermal stress applied during fabrication processing depends on the length of time spent at maximum processing temperature and the maximum temperature reached. PI is one of the most stable polymer materials at high temperature; glass transition temperature $(\mathrm{Tg})$ of $\mathrm{C}$. PI is higher than 330 ${ }^{\circ} \mathrm{C}$. Although the film was dissolved in acetone and dimethylformamide, the C. PI showed good solvent resistance against process chemicals such as acids, bases, photoresist (PR) developer, IZO etchant and PR stripper. Surface roughness of the substrate was equal to approximately $1 \mathrm{~nm}$ and maximum differences in height (peak-to-valley) are about 3-4 $\mathrm{nm}$.

A variety of IZO thin films as pixel electrode were produced under different deposition time conditions on the C. PI substrates, as shown in Table II, which enable to investigate the effects of IZO thickness.

Table II. Influence of IZO thickness on sheet resistance, transmittance, and haze properties.

\begin{tabular}{|c|c|c|c|c|}
\hline & $\begin{array}{c}\text { Thickness } \\
(\mathrm{nm})\end{array}$ & $\begin{array}{c}\text { Sheet } \\
\text { Resistance } \\
(\mathrm{ohm} / \mathrm{sq})\end{array}$ & $\begin{array}{c}\text { Transmittance } \\
(\%) \text { at 550nm }\end{array}$ & Haze \\
\hline IZO-1 & 120 & 42 & 86 & 0.3 \\
\hline IZO-2 & 160 & 29 & 85 & 0.4 \\
\hline IZO-3 & 200 & 23 & 82 & 0.4 \\
\hline
\end{tabular}

A considerable decrease of sheet resistance and light transmittance was investigated with increasing IZO thickness. The sheet resistance of IZO series with dimension of $10 \times 10 \mathrm{~cm}^{2}$, which showed good uniformity in electrical properties as shown in Fig. 1, was indeed reduced from $42 \mathrm{ohm} / \mathrm{sq}$ to $23 \mathrm{ohm} / \mathrm{sq}$ with increasing IZO thickness. The sheet resistance of IZO films hardly changed with the range of thermal treatment (at $180{ }^{\circ} \mathrm{C}$ until $\sim 6 \mathrm{~h}$ ) examined, even though thermal expansion of the C. PI substrate induced significant amounts of tensile stresses in IZO layer ${ }^{11}$.

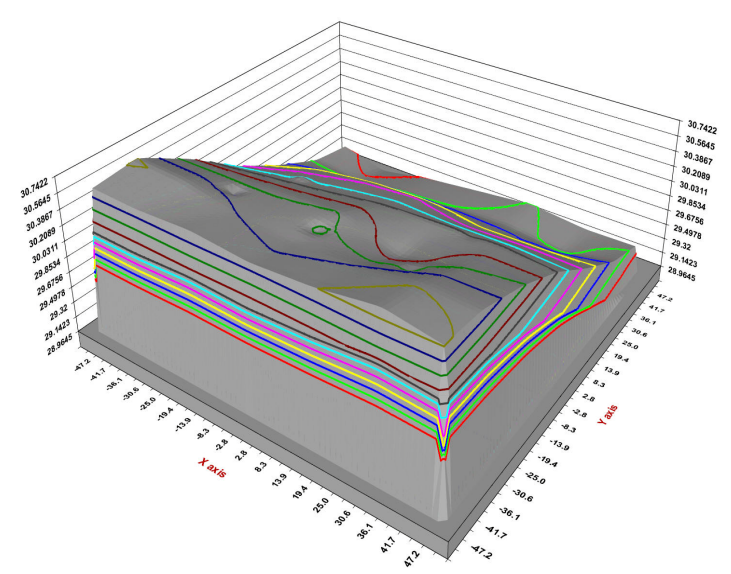

Fig.1 3D map analysis on sheet resistance of IZO-2 (thickness, $160 \mathrm{~nm}$ ) with dimension of $10 \times 10 \mathrm{~cm}^{2}$ (Max, $30.74 \mathrm{ohm} / \mathrm{sq}$; Min, $28.96 \mathrm{ohm} / \mathrm{sq}$; Avg., $29.98 \mathrm{ohm} / \mathrm{sq}$; Uniformity (\%), 2.96) 
To measure durability of the IZO-series, we designed bending machine that has first electrode and second electrode parts in horizontal direction. The first electrode is fixed so that the second electrode part horizontally moves toward the first electrode part to apply mechanical stress of the horizontal direction. The first and second electrode parts have clamps having grooves in which the one side and the other side of the IZO-series are inserted. We measured resistance between first and second electrodes during bending motion.

Substantial variations in the resistance of the obtained IZO-series under high strain condition (bending radius, $10 \mathrm{~mm}$; accumulated times of bending motion, 10000) was not observed. As shown in Fig. 2, we could obtain a small change $(\sim 1.0 \%)$. The obtained amorphous IZO, which are adequate for bendable electronic devices, shows excellent patterning behavior, high and uniform etching rate during wet etching process and absence of etching residue ${ }^{12-14)}$.

We next fabricated a 3-inch C. PI-based LCD clock by using sheet-to-sheet freestanding process without support of any carrier substrates. To drive the flexible LCD clock, control box and on/off switching jig were designed. Flexible LCD process requires masking and patterning by use of etchant and developer. The C. PI substrate endures such process hardship during LCD manufacturing. In fabrication process, much attention was paid to the influence of density and position of spacers, width of seal line and assembly pressure conditions for ensuring of cell gap uniformity.

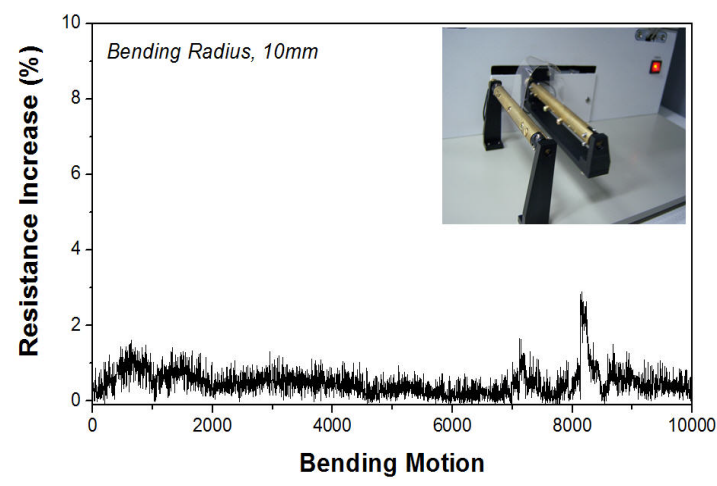

Fig.2 The sheet resistance changes of C.PI with IZO-2 electrode (bending radius, $10 \mathrm{~mm}$ )

Figure 3 shows the LCD clock driven by a.c. bias voltage $(50 \mathrm{~Hz})$ of $3.5 \mathrm{~V}$. NLC in the cell without an electrical field are aligned parallel to the C. PI substrate (homogeneous alignment) and thus exhibit maximum transmittance.

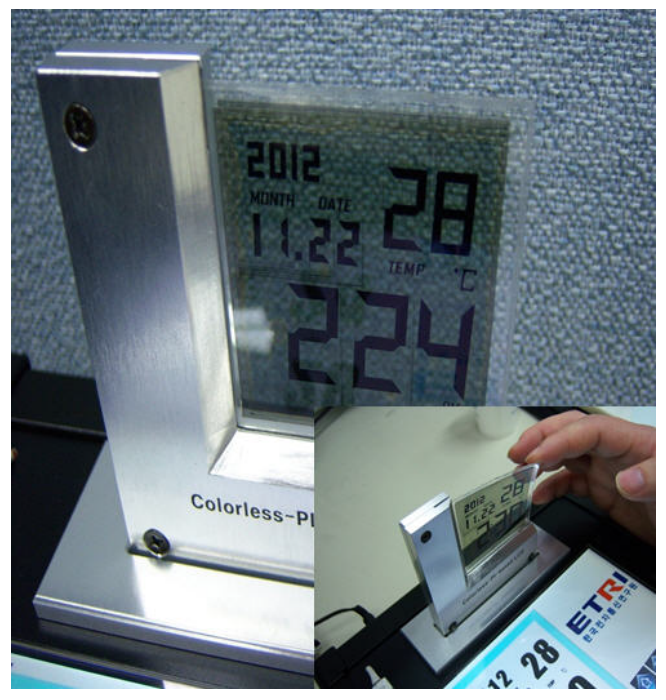

Fig.3 C. PI-based TN-LCD clock with IZO-2 driven by an a.c. bias voltage $(50 \mathrm{~Hz})$ of $3.5 \mathrm{~V}$.

Figure 4 shows the transmission-voltage $(\mathrm{T}-\mathrm{V})$ profile of the clock. It was observed that with increasing applied a.c. voltage across the cell, the transmittance decreased and eventually reached to dark state. Its maximum contrast ratio is $826: 1$.

This is well known as an electro-optic effect of TN-NLC, which results from change in alignment of NLC from homogeneous to homeotropic alignment ${ }^{9}$. This behavior is affected by alignment layer thickness and cell gap.

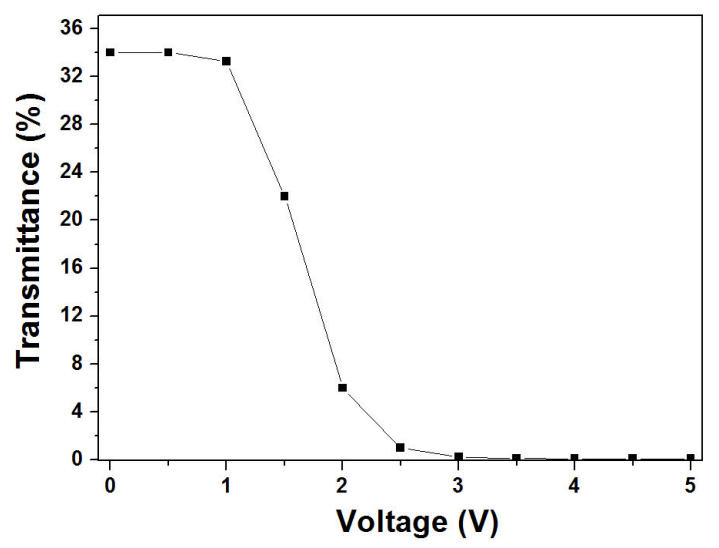

Fig.4 The electro-optical response of TN-LCD clock with IZO-2 electrode (thickness, $160 \mathrm{~nm}$ ) at $25{ }^{\circ} \mathrm{C}$ (Rubbing depth, $1.2 \mathrm{~mm}$ ).

Cell gap of the LCD is very homogeneous in the range of 3.61-3.81 $\mu \mathrm{m}$. The field-on response time $\mathrm{Tr}$ (field-off response time $\mathrm{Tf}$ ) is the time taken for the transmission to change from $90 \%(10 \%)$ to $10 \%(90 \%)$ by an electric field. The response time of on/off operation was about $12.0 \mathrm{~ms}$ (Fig. 5). Tr and Tf were times were $1.1 \mathrm{~ms}$ and $10.9 \mathrm{~ms}$, respectively.

Fig. 5 shows time lag between Tf and Tr. Field-on response time $\mathrm{Tr}$ and field-off response time $\mathrm{Tf}$ depend on the cell gap $d$, viscosity $\eta_{1}$ and effective elastic constant $\mathrm{K}_{22}$ as followed: 


$$
\begin{aligned}
& \operatorname{Tr}=\frac{\eta_{1}}{\varepsilon_{o}\left(a b s(\Delta \varepsilon) E^{2}-K_{22} \pi^{2} / d^{2}\right.} \\
& \operatorname{Tf}=\frac{\eta_{1} d^{2}}{\pi^{2} K_{22}}
\end{aligned}
$$

These equations are derived for a pure glass-based TN-LC device ${ }^{15)}$. In flexible TN-LC device, Tf can influence by metal impurities in LC and alignment layer, flexibility of plastic substrate and azimuthal anchoring energy (AAE). NLC used in this study shows purity of about $99.8 \%$ and has metal impurities of above $50 \mathrm{ppb}$. Its impurity level is a relatively high. When C. PI film is rubbed, a flexibility of the film impedes the alignment of PI molecules with the rubbing directions. Plastic films having flexibility might be pressed during rubbing that might induce weak azimuthal anchoring energy. NLC purity and weak azimuthal anchoring energy might affect the response time ( $\mathrm{Tf}$ ) of the device. The response time of on/off operation was dependent on the rubbing strength (Table III).

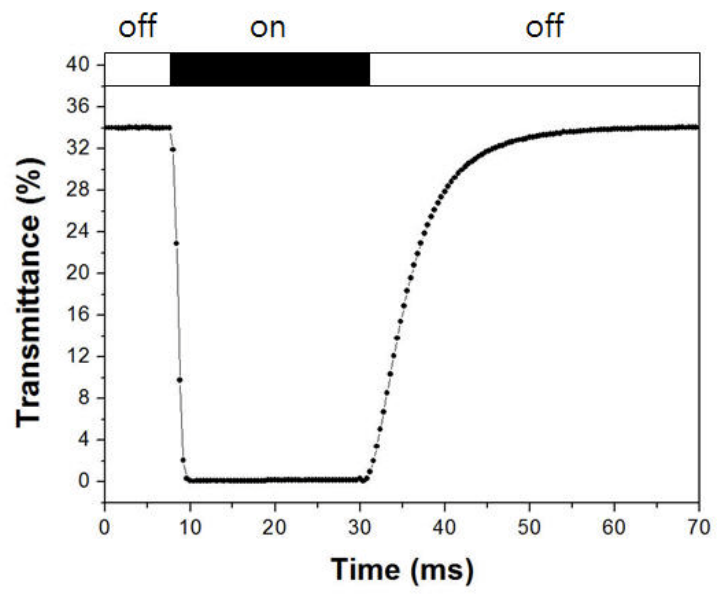

Fig. 5 The response time of TN-LCD clock with IZO-2 electrode (thickness, $160 \mathrm{~nm}$ ) with an a.c. bias voltage of $3.5 \mathrm{~V}(50 \mathrm{~Hz})$ (Rubbing depth, $1.2 \mathrm{~mm})$.

Table III. Electro-optic performance of C.PI-based TN-LCD as a function of rubbing depth (mm)

\begin{tabular}{|c|c|c|c|}
\hline $\begin{array}{c}\text { Rubbing } \\
\text { Depth } \\
(\mathrm{mm})\end{array}$ & $\begin{array}{c}\text { Rubbing } \\
\text { Strength } \\
(\mathrm{L}, \mathrm{mm})\end{array}$ & $\begin{array}{c}\text { Contrast } \\
\text { Ratio }\end{array}$ & $\begin{array}{c}\text { Response } \\
\text { Time(ms) } \\
(\mathrm{Tr} / \mathrm{Tf})\end{array}$ \\
\hline 0.7 & 263.4 & $670: 1$ & $40.80(15.02 / 25.78)$ \\
\hline 1.0 & 314.4 & $725: 1$ & $22.37(7.33 / 15.04)$ \\
\hline 1.2 & 344.2 & $826: 1$ & $12.0(1.1 / 10.9)$ \\
\hline
\end{tabular}

\section{CONCLUSIONS}

C. PI substrate has been demonstrated; the film has high thermal stability, surface smoothness, optical transparency and chemical resistance, which showed very small changes in chemical/physical properties before and after thermal/chemical treatment. IZO thin films as pixel electrode were deposited onto the C.PI. Even though IZO coatings are susceptible to crack and delaminate when plastic films stretched, twisted or bended, the resistance of IZO films showed a very small change $(\sim 1.0 \%)$ under severe bending motion (bending radius, $10 \mathrm{~mm}$ ). The IZO coated C.PI substrate is a good candidate for flexible electronic.

To explore the performance of the C. PI substrate, we fabricated a 3 -inch TN-LCD clock. Some fabrication issues for flexible LCD are solved, and we achieved C. PI-based LCD with well-controlled cell gap uniformity and good electro-optic characteristics.

\section{ACKNOWLEDGEMENTS}

This work was supported by the grant from the Industrial technology development program of the Ministry of Knowledge Economy (MKE) of Korea.

\section{REFERENCES}

[1] Displaybank, "Flexible display substrate technology and development trend (2008-2020)" (2008).

[2] M. A. M. Leenen, V. Arning, H. Thiem, J. Steiger and R. Anselmann, Phys. Status Solidi A, 206, 588-597 (2009).

[3] W. A. MacDonald, J. Mater. Chem., 14, 4-10 (2004).

[4] G. H. Kim, S. M. Yoon and H. A. Chun, Proceeding of IDW'09, 823-824 (2009).

[5] NanoMarkets, "Flexible Substrates Markets-2012", (2011) pp. 20-36.

[6] T. Nakao, S. Shibahara and W. Oka, Proceeding of IDW'03, 621-624 (2003).

[7] G. Rochat, Y. Letterier, P. Fayet and J.-A.E. Manson, Thin Solid Films, 437, 204-210 (2003).

[8] C. Thiele and R. Das, "Transparent Conductive Films 2012-2022", IDTechEx (2011) pp. 37-50.

[9] G. H. Kim, S. Enomoto, A. Kanazawa, T. Shiono and T. Ikeda, Liq. Cryst., 28, 271-277 (2001).

[10] H. T. Kim and J. K. Park, Polymer J, 29, 1002 (1997).

[11] Y. Leterrier, L. Mdico, F. Demarco, J. -A. E. Manson, U. Betz, M. F. Escola, M. K. Olsson and F. Atamny, Thin Solid Films, 460, 156-166 (2004).

[12] B. M. Henry, A. G. Erlat, A. McGuigan, C. R. M. Grovenor, G. A. D. Briggs, Y. Tsukahara, T. Miyamoto, N. Noguchi and T. Niijma, Thin Solid Films, 382, 194-201 (2001).

[13] J. -K. Lee, S. -S. Kim, Y. -I. Kim and Y. -K. Hwang, Solid-State Electronics, 56, 159-162 (2011).

[14] Z. Li, K. -H. Wong, Y. Gong, and M. M. -Y. Chang, Multimedia Tools and Applications, 1-20 (2011). [15] C. Y. Huang, Y. S. Chin and S. W. Ke, Appl. Phys. $B, 86,123-127$ (2007).

(Received February 22, 2013; Accepted April 14, 2013) 